\title{
British motor neuron disease twin study
}

\author{
A J Graham, A M Macdonald, C H Hawkes
}

\begin{abstract}
Objectives-To investigate the cause of sporadic motor neuron disease (MND) by twin study, so allowing (1) estimation of the genetic contribution, and (2) collection of matched pairs for a case-control study of possible environimental factors. Methods-10 872 death certificates bearing the diagnosis MND were collected from 1979 to 1989 inclusive. Inspection of individual birth entries allowed identification of potential twins. The status of each co-twin was determined and contact made through the National Health Service Central Register (NHS-CR) and their general practitioner (GP). The diagnosis of MND was verified via the co-twin and relatives, and medical records where available. Zygosity was assessed using a recognised questionnaire. Details concerning environmental exposures and health were gathered by interview of cotwin and relatives using a semistructured questionnaire. Heritability $\left(h^{2}\right)$ of $M N D$ was estimated, and the environmental information was analysed by conditional logistic regression modelling.
\end{abstract}

Results-Seventy seven probands were identified, of whom 26 were monozygotic and 51 dizygotic. Four monozygotic probands were concordant, but two probands came from a family known to have familial MND. The estimated heritability was between 0.38 and $0 \cdot 85$. Most environmental risk factors were not significant. Regular vehicle maintenance (odds ratio $(O R)=7 \cdot 0 ; 95 \%$ confidence interval (95\% CI) 1.3-89.9) and occupational paint usage $(O R=3.75 ; 95 \%$ CI $1 \cdot 0-17 \cdot 1)$, however, occurred significantly more often in the affected cases.

Conclusions-This "death discordant" method for twin collection has proved to be viable, and has allowed the ascertainment of a large population sample in a rare disease. The genetic role in sporadic MND is substantial, and higher than expected. Exposure to industrial chemicals, particularly constituents of petrochemicals and paints, may contribute to the aetiology of MND.

(F Neurol Neurosurg Psychiatry 1997;62:562-569)

Keywords: motor neuron disease; twin study; mortality data; case-control study
Familial aggregation of motor neuron disease (MND) was first acknowledged in $1955,{ }^{1}$ and has been estimated to range between $5 \%$ and $10 \%$ of the total incidence of MND. ${ }^{23}$ Similar familial patterns are seen in $5 \%-10 \%$ of cases of Alzheimer's disease ${ }^{4}$ and $15 \%-20 \%$ of cases of Parkinson's disease. ${ }^{5}$ Familial does not necessarily mean genetic, and non-genetic shared environmental factors could be important. Many familial MND pedigrees exhibit autosomal dominant patterns of inheritance, ${ }^{67}$ with an equal male:female ratio. ${ }^{8}$ Other pedigrees seem to show dominant inheritance but with incomplete penetrance, ${ }^{69}$ which is associated with the wide age range of disease onset or predisposition to early death from another cause. ${ }^{10}$

In such a rare disease the familial-sporadic distinction may be difficult to make reliably, as apparently sporadic cases may simply be due to the low prevalence. In familial MND tight genetic linkage has been shown between a familial MND marker and a gene found on chromosome $21 \mathrm{q}$ that encodes a cytosolic CU/ZN-binding superoxide dismutase (SOD1). ${ }^{11}$ This is a homodimeric metalloenzyme, the altered activity of which may lead to accumulation of neurotoxic free radicals. ${ }^{12}$ It is possible that similar genetic factors may also play a part in apparently sporadic cases of MND; three cases of non-familial MND have been described with the SOD1 mutation. ${ }^{13}$

The classic twin study

The relative importance of genetic and environmental factors in disease aetiology can be assessed by studying twins. ${ }^{14}$ This is a first step in the study of most diseases, as the interactions of genetic and environmental factors are likely to be of most importance in the search for prevention and cure. The frequency of the relevant disease occurring in both members of a twin pair is calculated (concordance), and the concordance rates of identical and fraternal twins compared. If the concordance rate for the study disease is high in pairs of identical (monozygotic) twins, and much lower for fraternal (dizygotic) twins, then this implies a major genetic influence, strongly related to prevalence of disease. Equal concordance in monozygotic and dizygotic twins implies that environmental influences are more important.

When ascertainment of affected cases appropriately samples the population, concordance rates may be used to derive estimates for inheritance of liability, ${ }^{15} 16$ by analysing the 
rates in combination with prevalence rates. ${ }^{17}$ This provides a quantitative estimate of the extent of genetic influences on the disease in the sample.

There have been no previous systematic twin studies of MND to provide an indication of the relative importance of genes and environment, only some case study reports, ${ }^{18-20}$ and a case-control study of discordant pairs using a sample recruited by advertisements. ${ }^{21}$

The case-control twin study

Twins may be considered as matched pair case-controls for the study of disease aetiology. ${ }^{22}$ They have an additional advantage over other matched pair designs in that they are also genetically matched, monozygotic twins sharing $100 \%$ of their genes and dizygotic twins $50 \%$ on average. Some over matching of early shared environment could occur, as the twins are usually reared together in the same family. However, the examination of pairs of twins discordant for MND provides another useful method for clarifying the possible role of environmental risk factors said to be important in MND. ${ }^{23}{ }^{24}$ The present report provides brief details of environmental factors found to be significantly associated with risk for MND (to occur more often in the affected probands than in their unaffected co-twins) or to protect against it (to occur less often in the affected probands).

\section{Methods}

A population based twin study was chosen to examine the relative genetic and environmental contribution to sporadic MND. This design incorporates the collection of a systematically ascertained sample of twins which will be representative of the diseased population, provided the general principles of such studies are followed.

Traditional methods of twin pair ascertainment would have provided a very small sample within Great Britain (19-34 pairs). Therefore, a novel methodology was devised using mortality data from which twins were identified and their co-twins traced. A comprehensive description and evaluation of this methodology was published recently. ${ }^{25}$ Briefly, details of all registered deaths due to MND in England and Wales from 1979 to 1989 were matched against birth records of the individual patients (9371 cases) and all the twin births identified. The current status of the co-twins and their whereabouts were then traced through the National Health Service Central Register (NHS-CR) system.

VALIDATION OF MND DIAGNOSIS IN CASE TWINS Attempts to validate the diagnosis were made by requesting hospital and general practice records using information given on the death certificate. Records were only available for a limited number of patients (20), because many records had already been destroyed. A neurologist studied those remaining to verify the death certificate diagnosis and all intervie- wees were questioned about the index twin's symptoms and progression of illness.

\section{Detection of MND in living co-twins}

Living co-twins (47) were questioned about the common signs and symptoms of early $M N D$, and about contact with their general practitioner (GP). If the co-twin gave a history of any neurological or muscular symptoms suggestive of $M N D$, this was verified with the co-twin's GP (two). It was not necessary to refer either of the co-twins to a neurologist.

\section{ZYGOSITY VERIFICATION}

A questionnaire devised by Magnus et al 1983 which focuses on the similarities within twin pairs was used. ${ }^{26}$ This has been shown to be accurate in establishing zygosity in $97.6 \%$ of cases, if both members of a pair answered the questionnaire, and $96 \cdot 1 \%$ if only one twin was used. ${ }^{26}$ Childhood photographs of the twins were requested to help confirm zygosity.

\section{ENVIRONMENTAL RISK: CASE CONTROL}

\section{ASSESSMENT}

A questionnaire was designed to investigate the twins' lifestyles, thus enabling an estimation of exposure to specific factors as highlighted in previous investigations to be of possible relevance. ${ }^{23} 24$ This, together with a semistructured interview of surviving relatives, had been piloted on a group of siblings and spouses of non-twin patients with MND.

DATA ANALYSIS AND STATISTICAL METHODS The analysis of the data was divided into three sections:

\section{(1) Overview of the twin sample}

To establish whether the twin sample was representative, a two sample $t$ test was used together with a $z$ test for two independent groups.

(2) Determination of the genetic contribution to $M N D$

Heritability was calculated in standard fashion as twice the difference between monozygotic and dizygotic correlations in liability. ${ }^{1627}$ Tetrachoric correlations of liability were calculated from the proband concordance rates, ${ }^{17} 28$ for which standard errors and $95 \%$ confidence intervals (95\% CIs) were calculated. ${ }^{29}$

(3) Results from the environmental questionnaire Analysis of this data was carried out using statistical methods for matched pairs. Odds ratios (ORs) with 95\% CIs were calculated using the methods given by Schlesselman and Altman for proportional data. ${ }^{22} 30$ Significance of the ORs was found using McNemar's test including a continuity correction for small numbers. This produces conservative results. The influence of different environmental factors on the estimated risk of being afflicted with MND were also analysed by conditional logistic regression using the statistical package GLIM (generalised linear interactive modelling).

In view of the small sample size the different sex twin pairs were included in the analysis of 
the environmental factors. Although these pairs were not strictly matched as the same sex twins, this decision was justified because the group contained equal numbers of male and female cases and controls, which allows the balancing of exposures that could be sex related.

\section{Results}

OVERVIEW OF SAMPLE

A total of 128 pairs, in which at least one twin died from MND, were identified from the study population which comprised 9371 cases (MND deaths) during the period 1979-89. This gives a twinning rate of 1:70 live births between $1900-50$, which is slightly greater than the first published rate of 1:80 live births in 1938-40. ${ }^{31}$ Meticulous tracing strategies for the co-twins identified the following co-twin status: 58 living, 31 adult deaths, 29 infant deaths, and 10 untraceable.

The co-twins of two previously defined index cases, who also died from MND, were identified independently during death certificate processing and therefore regarded as index twins. This gave a sample of 130 probands. When those with co-twins who were untraceable or died in infancy were disregarded, the 130 probands reduced to 91 probands.

Sixty eight $(74 \cdot 7 \%)$ probands had same sex co-twins and $23(25 \cdot 3 \%)$ had different sex cotwins (table 1). The sex distribution among the probands was 50 males and 41 females, a ratio of $1 \cdot 2: 1$, and the mean age at death was 63.4 (SD 9.6), with a range of 37-85 years.

Probands with living co-twins

Forty seven of the 58 living co-twins agreed to be interviewed. Of the remaining 11 , two lived abroad, access to two was denied by the GP because of ill health (one with senile dementia, one with psychotic depression), and seven refused to participate. However, of these 11, relatives of six probands supplied some information about the twin pairs concerned, including probable zygosity. The remaining five consisted of two different sex pairs; and the zygosity of the others was obtained from the co-twin, or their medical records, via their GP. These GPs also confirmed that the cotwins did not have MND.

Probands with adult death co-twins

Positive contact was made with the relatives of 19 probands when both twins had died. Attempts to contact the others were unsuc-

Table 1 Twin type and sex distribution of the proband sample

\begin{tabular}{|c|c|c|c|c|c|c|c|}
\hline \multirow[b]{2}{*}{$\begin{array}{l}\text { Twin sample } \\
\text { portion }\end{array}$} & \multirow[b]{2}{*}{$\begin{array}{l}\text { Twin } \\
\text { pairs } \\
n\end{array}$} & \multicolumn{3}{|c|}{ Like-sexed pairs } & \multicolumn{3}{|c|}{ Unlike-sexed pairs } \\
\hline & & $n(\%)$ & $\begin{array}{l}\text { Males } \\
n\end{array}$ & $\begin{array}{l}\text { Females } \\
n\end{array}$ & $n(\%)$ & $\begin{array}{l}\text { Female } \\
\text { co-twin } \\
n\end{array}$ & $\begin{array}{l}\text { Male } \\
\text { co-twin } \\
n\end{array}$ \\
\hline Twin sample & 91 & $68(74 \cdot 7)$ & 39 & 29 & $23(25 \cdot 3)$ & 11 & 12 \\
\hline $\begin{array}{l}\text { portion } \\
\text { Adult death }\end{array}$ & 58 & $45(77 \cdot 6)$ & 23 & 22 & $13(22 \cdot 4)$ & 8 & 5 \\
\hline co-twin portion & 33 & $23(69 \cdot 7)$ & 16 & 7 & $10(30 \cdot 3)$ & 3 & 7 \\
\hline
\end{tabular}

cessful (12). The participating relatives provided some information regarding the lifestyles of both twins, including probable zygosity.

\section{ZYGOSITY VERIFICATION}

No information was available for 10 out of 68 same sex probands. Among the remaining 58, questionnaire data identified 25 monozygotic and 30 dizygotic probands and GPs provided information about the remaining three probands. Thus 26 monozygotic and 32 dizygotic probands were identified, of which two monozygotic pairs were double proband pairs-that is, both died from MND. Nineteen pairs of different sex probands and co-twins were included in the genetic calculations, giving a total of 77 probands with reliable zygosity diagnosis.

\section{DETERMINATION OF THE GENETIC}

\section{CONTRIBUTION TO MND}

No co-twins had symptoms of MND at interview. None of the co-twins who died from other disorders before the study period had undisclosed MND according to the relatives interviewed. Therefore among this twin sample, four monozygotic probands from two pairs were identified as concordant for MND, but no dizygotic pairs were found to be concordant.

Before a concordance rate for sporadic MND among monozygotic twins was calculated, two factors had to be considered: (1) The removal of any concordant monozygotic probands with a family history of MND suggesting the inheritance of autosomal dominant familial MND. ${ }^{27}$ This resulted in the exclusion of two probands from one concordant pair: (2) The possible delay of MND developing in subsequent family members as suggested by the age variation in familial MND pedigrees. It was decided that when the co-twin died before the proband (three monozygotic pairs and seven dizygotic pairs), these pairs should not be considered discordant for the disease when determining the concordance rate and were therefore excluded from the calculations.

\section{Monozygotic probandwise concordance rate}

The monozygotic probandwise concordance rate $-15 \cdot 4 \%$ (SEM $7 \cdot 1 \%$ ), or binomal exact 95\% CI $4.4 \%-34.9 \%$ ) -was calculated using the basic monozygotic proband numbers obtained (four concordant probands out of 26). However, after removing from the calculation the concordant probands with familial MND and those probands with a co-twin dying before themselves, the amended monozygotic proband concordance rate was 9.5\% (SEM 6.4\%), or binomial exact $95 \% \mathrm{CI}$ : $1 \cdot 2 \%-30 \cdot 4 \%$ - that is, two concordant probands out of 21 . In turn this produced the following estimate for the monozygotic "correlation of liability", ${ }^{15}$ " $r "=0.717$ (SEM $0 \cdot 130)$, or in percentage terms " $\mathrm{r}$ " $=71.7 \%$ (SEM 13\%), based on an MND prevalence of 5:100 000. These figures are founded on one pair only, but confidence that this figure truly reflects the genetic influence in MND is supported by the pair being female, therefore their 
Table 2 Positive environmental factors in order of their odds ratio (OR) value, with 95\% CIs and significance

\begin{tabular}{|c|c|c|c|}
\hline Variable & $\begin{array}{l}\text { Discordant } \\
\text { pairs, (only } \\
\text { one exposed) } \\
n\end{array}$ & OR $(95 \% C I)$ & Pvalue \\
\hline Car/vehicle maintenance & $\begin{array}{l}\text { Cases } 14 \\
\text { Controls } 2\end{array}$ & $7 \cdot 00(1 \cdot 33-89 \cdot 90)$ & 0.006 \\
\hline Crafts using chemicals & $\begin{array}{l}\text { Cases 13 } \\
\text { Controls } 3\end{array}$ & $4 \cdot 33(1.02-27 \cdot 58)$ & 0.024 \\
\hline Paints used in job & $\begin{array}{l}\text { Cases } 15 \\
\text { Controls } 4\end{array}$ & $3 \cdot 75(1 \cdot 05-17 \cdot 12)$ & 0.022 \\
\hline Metal machining/fitting & $\begin{array}{l}\text { Cases } 5 \\
\text { Controls } 2\end{array}$ & $2 \cdot 50(0 \cdot 34-37 \cdot 46)$ & NS \\
\hline Vehicle trades & $\begin{array}{l}\text { Cases } 5 \\
\text { Controls } 2\end{array}$ & $2 \cdot 50(0 \cdot 34-37 \cdot 46)$ & NS \\
\hline Non-professional social class & $\begin{array}{l}\text { Cases } 16 \\
\text { Controls } 8\end{array}$ & $2.00(0.71-3.63)$ & NS \\
\hline Petrochemical length/time & $\begin{array}{l}\text { Continuous } \\
\text { variable }\end{array}$ & $1 \cdot 49(0 \cdot 78-2 \cdot 82)$ & NS \\
\hline DIY regularity & $\begin{array}{l}\text { Continuous } \\
\text { variable }\end{array}$ & $1.36(0.90-2.05)$ & $<0.05$ \\
\hline
\end{tabular}

disorder cannot have been Kennedy's syndrome, and that there was no suspicion of any other affected family members. These twins died from a rapidly progressing MND within 20 months of each other, aged 57 and 59.

\section{Dizygotic probandwise concordance rate} It was not possible to directly calculate a probandwise concordance rate for the dizygotic twins as no concordant dizygotic pairs were found, an indication of the difficulty of studying a rare disease. Two logical alternatives can be applied to provide estimates of the dizygotic concordance rate so that heritability estimates can be made. These are: (1) using the sibling rate for the disease calculated from all the siblings who lived to adulthood ( $>20$ years) among the twins' families. In a total population, sibling rate should equal dizygotic concordance rate; and (2) calculating the dizygotic probandwise concordance rate for the twin sample obtained, assuming that the next case identified through death certification who is from a dizygotic pair, is found to be concordant for MND after the co-twin has been traced. This technique has been used elsewhere. ${ }^{32}$

These two solutions can be used to provide estimated boundaries for the dizygotic concordance rate. If it is assumed that the next dizygotic proband identified would be from a pair concordant for MND, the estimate for dizygotic concordance would be $2 \cdot 22 \%$ (SEM $2 \cdot 20 \%$, or binomial exact $95 \%$ CI: $0.06 \%$ $11 \cdot 8 \%)$. Among the sibling data collected for the study twins, only one in 399 had probable

Table 3 Negative environmental factors in order of their odds ratio (OR) value, with 95\% CIs and significance

\begin{tabular}{llll}
\hline & $\begin{array}{l}\text { Discordant } \\
\text { pairs, (only } \\
\text { one exposed }) \\
n\end{array}$ & OR $(95 \%$ CI) & P value \\
Variable & $\begin{array}{l}\text { Continuous } \\
\text { variable }\end{array}$ & $0.79(0.59-1.03)$ & $0.06>$ P $>0.05$ \\
\hline Surgical operation (n) & $\begin{array}{l}\text { Cases 6 } \\
\text { Controls 17 }\end{array}$ & $0.35(0.11-1.04)$ & 0.037 \\
Head injury & $\begin{array}{l}\text { Cases 2 } \\
\text { Controls 10 }\end{array}$ & $0.20(0.015-1 \cdot 14)$ & 0.039 \\
Heart disease & $\begin{array}{l}\text { Cases 1 } \\
\text { Controls } 7\end{array}$ & 0.143 (near 0-1.44) & NS \\
Endocrine disorder & $\begin{array}{l}\text { Cases 1 } \\
\text { Controls 8 }\end{array}$ & 0.125 (near 0-1.21) & 0.039 \\
Malignant neoplasm & & & \\
\hline
\end{tabular}

MND, giving an estimate for dizygotic concordance of $0.25 \%$ (SEM $0.25 \%$, or binomial exact $95 \%$ CI $0 \%-1 \cdot 4 \%$ ). Using these figures to calculate the estimated limits of dizygotic "correlation of liability" " $r$ " fell between 0.53 (SEM 0.10) and 0.29 (SEM 0.004).

\section{Genetic contribution to sporadic MND}

By using the proxy dizygotic correlations, the range in which the estimate heritability $\left(\mathrm{h}^{2}\right)$ lies can be calculated. ${ }^{16}$ Using $\mathrm{h}^{2}=$ $2\left(r_{M Z}-r_{D Z}\right), h^{2}$ ranged between 0.38 and 0.85 , (using " $r$ " for the next affected case estimate and " $r$ " from the sibling rate respectively).

THE ENVIRONMENTAL QUESTIONNAIRE DATA As monozygotic twins comprised only one third of the sample, all monozygotic and dizygotic pairs were included in case-control analysis. Data were available from 70 pairs of discordant twins. Eight possible risk factors for MND were identified when the environmental variables were analysed individually (table 2 ). There were also five factors which appeared to be associated with protection from MND (table 3).

Many variables were examined in this exploratory analysis, because there are few consistent known risk factors for MND but many have been suggested. ${ }^{2324}$ This produced a total of 13 significant results, some of which may have been chance findings because of the many variables investigated, and therefore the significance levels should be interpreted conservatively. To take account of this, a multivariate approach was taken and the significant variables were subjected to conditional logistic regression, which allows for the related effects of several variables on each other to be taken into account.

\section{CONDITIONAL LOGISTIC REGRESSION} MODELLING

One variable which was significant in univariate analyses-head injury-was excluded from the conditional logistic regression model, because of the large number of twin pairs with missing data for this variable. All other significant variables (tables 2 and 3 ) were used to construct a conditional logistic regression model. Twelve death discordant pairs used in the individual variable analysis above, were excluded in the conditional logistic regression model because of incomplete data across all variables.

After manipulation of the conditional logistic regression model by fitting different combinations of the variables, only two were found that consistently contributed to the model at a significant level ("occupational paint exposure" and "carrying out car/vehicle maintenance" on a regular basis). All the others were therefore removed from the final model. Within the conditional logistic regression model selected, occupational paint exposure yielded an OR = 1.68 (95\% CI 0.96-2.94); and car/vehicle maintenance yielded an OR $=9.68(95 \% \mathrm{CI}$ 1.23-74-47).

The combined risk of these two variables with regard to MND was significant $(p<$ 
Table 4 Comparison of the characteristics of the complete twin sample with the MND death certificate population

\begin{tabular}{ll}
\hline MND death certificate population & Complete MND twin sample \\
\hline Mean age at death $66 \cdot 4(\mathrm{SD} 10 \cdot 4)$ y & Mean age at death $64 \cdot 5(\mathrm{SD} 10 \cdot 1) \mathrm{y}$ \\
Age range 13-89 y & Age range 33-85 y \\
Male:female ratio $1 \cdot 2: 1$ & Male:female ratio $1 \cdot 3: 1$ \\
Twin type proportions $1938-40$ & MND twin sample proportions \\
Like-sexed twins $64 \cdot 4 \%$ & Like-sexed twins $67 \cdot 2 \%=86$ \\
Unlike-sexed twins $35 \cdot 6 \%$ & Unlike-sexed twins $32 \cdot 8 \%=42$ \\
\hline
\end{tabular}

$0 \cdot 001)$. In addition to these two variables there were two others that when added to the logistic regression model together contributed an increased risk of MND which was just short of significance. These were the DIY regularity and non-professional social class variables.

All the other factors investigated had no apparent influence on MND with similar experiences of exposure reported for both twins.

\section{Discussion}

METHODOLOGICAL ISSUES AND TWIN STUDIES There has been recently some debate as to the true value and interpretation of using twins to investigate the genetic influence in particular diseases. Phillips argued that the adverse prenatal environment of monozygotic twins, relative to dizygotic twins, will result in increased monozygotic concordance and fallacious overestimate of genetic aetiology. ${ }^{33}$ Many others, however, disagree, ${ }^{34} 35$ and advocate the value of twins to medical research. For example, Macdonald pointed out that because monozygotic twins have greater within pair variability in their prenatal environment, then this will lead to discordance and make monozygotic twins less alike. ${ }^{36}$ Christensen et al found no significant difference in mortality among monozygotic and dizygotic twins older than 6 years and the general population. ${ }^{37}$ Methodological difficulties associated with conducting twin studies have justifiably resulted in criticism of their value. ${ }^{38}$ Many twin samples gathered are incomplete, skewed, and unrepresentative of the populations from which they were obtained, producing results which are meaningless and misleading. The aim of this twin method was to overcome these problems when investigating a rare disease.

\section{THE TWIN SAMPLE OBTAINED USING} MORTALITY DATA

The new methodology designed for this study has been successful, creating the largest population based sample of twins for the investigation of MND ever gathered. Many of the pitfalls associated with traditional twin studies have been overcome, especially that of biased subject selection, which occurs when using public appeal, ${ }^{3940}$ or when not all the twins within a population are identified because they are selected from hospital or medical records. ${ }^{41-43}$ The twin sample collected for this study is probably complete and unbiased, and therefore representative of the study population (table 4). The results are corroborated as follows.
(1) The prevalence of twins found in the MND death certificate population $(1: 70)$ is greater than that first published for 1938-40 (1:80) when the incidence of twin births was already declining, ${ }^{31}$ thus the method is not underascertaining twins.

(2) The proportion of same sex to different sex twins among the complete twin sample is comparable with the first published ratio.

(3) The sex ratio and age distribution of the twin probands at death were very similar to those found in the utilised MND death certificate population, and any differences were not significant.

(4) the study ratio of dizygotic:monozygotic twins (2:1) found among those whose zygosity was established (77 probands) was the same as the estimated ratio in the general population. ${ }^{27}$

As with all research methodologies, the death discordant twin method has weaknesses, as follows.

\section{Accuracy of death certification}

Reliance on the diagnosis certified at the time of death was one of the main problems with the death discordant twin method. The authenticity of the MND diagnosis in the probands could not be guaranteed. However, in retrospective studies in Britain and the United States $72 \%-91 \%$ of known cases of MND death certificates were found to quote the correct diagnosis. ${ }^{44-47}$ Appropriate questioning of the interviewees helped to confirm the probands' MND diagnoses and the medical records were examined where possible.

\section{Dependence on proxy information}

Another important weakness with this methodology was that information relating to the proband could only be obtained from their co-twin or relative. When using proxy information, error is likely to arise because the surrogate may not be able to provide detailed information about aspects of the proband's lifestyle. In an attempt to reduce this problem the spouse or other close relative of the proband was interviewed if possible.

\section{Loss of twin pairs from the sample}

The number of living co-twins traced (45.3\%) was less than expected for three reasons that were only quantified by doing a formal search of the co-twins. These were: (a) infant mortality resulting in the loss of $22.7 \%$ of the cotwins, with a disproportionate number being different sex twins. This will not have biased the twin sample as it is a population phenomenon affecting all twins born in England and Wales during the same time period; $(b)$ with the age range for MND development being 45-75 years for most patients, some co-twins succumbed to other diseases before or shortly after the index twin $(24 \cdot 2 \%)$. The methodology of this study allowed the ascertainment of such pairs, and therefore produced a more diverse twin sample than in conventional twin studies. When the co-twin died before the proband, the pair were excluded from the concordance rate calculations; (c) many female co-twins married before instigation of the 
NHS-CR in the late 1940s. Hence, it was very difficult to identify the correct marriage entries for women with fairly common surnames $(5 \cdot 5 \%)$.

\section{Twin zygosity}

Classification of zygosity was only possible by a single validated zygosity questionnaire, ${ }^{26}$ supported by childhood photographs. The results produced from this questionnaire for each twin pair were unambiguously classifiable as monozygotic or dizygotic. There is no reason to think that the accuracy shown by Magnus et al for single twin use (96.1\%) should be any lower among this twin sample, ${ }^{26}$ although its validity when determining zygosity of a twin pair when both are dead via a first degree relative is unknown.

Miscellaneous sources of possible biases Non-systematic bias may have occurred through: (a) human error during searching records for the co-twins; $(b)$ reaction of GPs to the study; (c) agreement or not of the co-twin to be interviewed. No co-twins; were lost through lack of response from GPs, but nine living co-twins were too ill or refused to be interviewed. A final potential source of bias could have arisen if the interviewer had preconceived ideas about the aetiology of MND, and thus unwittingly focused the interviews on supporting elements. To minimise this a tightly structured questionnaire was followed during each interview.

\section{THE GENETIC ELEMENT OF MND}

The conservative monozygotic probandwise concordance rate of $9.5 \%$ is small, but to be expected in a disease like MND which is rare $(0.005 \%$ or 5 per 100000$)$. It has been stressed that this does not mean heritability is negligible. ${ }^{48}$ The "correlation of liability" estimation is less reliable when the disease frequency is extremely small, so the calculated figure for the monozygotic twins $(0.717$ (SEM) 0.13 ) is probably an overestimation of the degree to which shared genetic factors determine the manifestation of $\mathrm{MND}$, although it clearly shows a significant contribution. The relatively small monozygotic twin sample means that the SEM quoted for the monozygotic "correlation of liability" is large, but does not negate the overall interpretation.

Although the use of the proxy dizygotic concordance rates gives a wide range of heritability, the finding that between $38 \%$ and $85 \%$ of variation in MND is due to inherited factors indicate that even in so-called sporadic MND, with a conservative approach to analysis of the data, genetic influences are significant.

\section{Familial MND}

Six per cent of the probands (four) had a family history of MND, which followed an autosomal dominant inheritance pattern. This is similar to that found in previous studies $(5 \%-10 \%))^{23}$ Interestingly, among the two multiple affected families with monozygotic probands, only one pair have both succumbed to the disease so far. The other pair have remained discordant up to interview $(6.5$ years) and were still discordant after a further two years.

ENVIRONMENTAL RISK FACTORS FOR MND

The results obtained from the case-control study of environmental exposures imply that exposure to petrochemicals, paints, and associated industrial chemicals increase the risk of developing MND. Evidence for this comes from the large ORs obtained individually for activities that involve exposure to such chemicals. Car/vehicle maintenance and occupational paint usage produced highly significant ORs individually and within the conditional logistic regression model. "DIY regularity" and non-professional social class individually produced ORs that were significant, or nearly significant at the accepted $P<0.05$ respectively, although they only produced a combined effect in the logistic regression model. Support for these findings related to two factors (car/vehicle maintenance; "non-professional social class") comes from the recent Decennial Supplement on Occupational Mortality, ${ }^{49}$ which reports that motor mechanics have an increased proportional mortality ratio of 139 (95\% CI 105-181) for MND.

The small numbers available for the casecontrol study may have resulted in insufficient power to detect other significant risk factors. In matched pair analysis, only the difference between the discordant pair data is considered, and for most variables investigated in this study involved only a small portion of the total sample. The two strongest variables (car/vehicle maintenance and occupational paint usage) had a $95 \%$ CI greater than $1 \cdot 0$, although all the other six positively associated variables from univariate analyses (table 2) had ORs that could be of clinical value. The nature of the exposure in most cases was chronic, rather than acute, which makes causative relations very difficult to identify, and by definition any statistical associations weak.

Interest in the possible role of noxious chemicals in the aetiology of MND has increased in recent times. Several studies of occupational data and MND have suggested a positive relation between $M N D$ and solvent exposure, ${ }^{50-53}$ although the occupations and chemicals involved have varied. Solvent exposure alone did not seem to be a risk factor for MND among the twin sample. Solvents as a group are so widely used in both industry and for domestic purposes that it is not surprising to find no direct relation. They are, however, important components used in conjunction with both petrochemicals and paints, and these may therefore have a positive relation with MND under certain conditions. There have been case reports of MND type syndromes developing after acute exposure to specific chemicals such as ant pesticide. ${ }^{54}$ The male preponderance of $\mathrm{MND}^{55-57}$ supports the likelihood that exposure to industrial chemicals has a significant causative role, as men are more likely to carry out activities using noxious chemicals. More subtle or hidden expo- 
sure could be sufficient to cause disease, but is very difficult to determine. Many co-twins reported only indirect contact, but may have experienced appreciable degrees of exposure of which they were unaware.

As MND is a neurodegenerative disease which exhibits increasing incidence with age, ${ }^{56-59}$ any environmental influence on its development is more likely to be of a chronic nature, possibly over long periods. Alternatively, the aging nervous system may become more sensitive, particularly the motor neurons to environmental assaults, ${ }^{60}$ so smaller amounts of chemicals may inflict increasing damage over shorter periods in susceptible people.

\section{Conclusions}

The study provides:

- A new methodology that facilitates the collection of a large twin sample in rare diseases, that is representative of the chosen population

- Collection of the largest twin sample reported for the investigation of MND

- Evidence that there is a genetic influence in the aetiology of so-called sporadic MND accounting for $38 \%-85 \%$ of the risk, leading to a predisposition for MND which is triggered by one or many exogenous factors

- Evidence to implicate industrial chemicals, particularly the constituents of petrochemicals and paints, in the aetiology of MND.

We acknowledge and express sincere gratitude to the following people who gave their support and assistance during this study: Professor C D Marsden, Institute of Neurology, London; Dr H Ashley, Dr A J Fox, Dr E Alberman, Mrs P Riach, and colleagues at the Office of Population Censuses and Surveys for England and Wales without whose cooperation this study could not have been undertaken: Ann Petruckevitch, Statistician at the Institute of Neurology; Dr D Coggon and Mr B Pannett, MRC Environmental Epidemiology Unit, University of Southampton: Motor Neurone Disease Association of England and Wales who provided the research grant: the co-twins and relatives who kindly participated in the study: the study was part of the PhD thesis of AJG (1994), which includes all details of the work.

1 Kurland LT, Mulder DW. Epidemiologic investigations of amyotrophic lateral sclerosis 2. Familial aggregations amyotrophic lateral sclerosis 2. Familial aggregations indicative

$2 \mathrm{Li} \mathrm{T-M}$, Alberman E, Swash M. Comparison of sporadic and familial disease amongst 580 cases of motor neuron disease. F Neurol Neurosurg Psychiatry 1988;51:778-84.

3 Tandan R, Bradley WG. Amyotrophic lateral sclerosis: par 1. Clinical features, pathology, and ethical issues in management. Ann Neurol 1985;18:271-80.

4 Fitch N, Becker R, Heller A. The inheritance of Alzheimer's disease: a new interpretation. Ann Neurol 1988;23:14-9.

5 Duvoisin RC. On heredity, twins and Parkinson's disease. Ann Neurol 1986;19:409-11.

6 Mulder DW, Kurland LT, Offord KP, Beard M. Familia adult motor neurone disease: amyotrophic lateral sclerosis. Neurology 1986;36:511-7.

7 Hawkes CH, Cavanagh JB, Mowbray S, Paul EA. Familial motor neurone disease: report of a family with five postmortem studies. In: Rose FC, ed. Research progress in motor neurone disease. Bath: Pitman, 1984:70-98.

8 Strong MJ, Hudson AJ, Alvord WG. Familial amyotrophic lateral sclerosis, 1850-1989: a statistical analysis of the world literature. Can $\mathcal{F}$ Neurol Sci 1991;18:45-58.

9 Chió A, Brignolio F, Meineri P, Schiffer D. Phenotypic and genotypic heterogeneity of dominantly inherited amyotrophic lateral sclerosis. Acta Neurol Scand 1987, 75:277-82.

10 Williams DB, Floate DA, Leicester J. Familial motor neurone disease: differing penetrance in large pedigrees. Neurol Sci 1988;86:215-30.

11 Rosen DR, Siddique T, Patterson D, Figlewicz DA, Sapp $\mathrm{P}$, Hentati $\mathrm{A}$, et al. Mutations in $\mathrm{Cu} / \mathrm{Zn}$ superoxide dismutase gene are associated with familial amyotrophic lateral sclerosis. Nature 1993;362:59-62.

12 McNamara JO, Fridovich I. Did radicals strike Lou
Gehrig? Nature 1993;362:20-1.

13 Jones CT, Brock DJH, Chancellor AM, Warlow CP, Swingler RJ. Cu/Zn superoxide dismutase (SOD1) mutations and sporadic amyotrophic lateral sclerosis. Lancet tions and sporadic

14 Hrubec Z, Robinette CD. The study of human twins in medical research. $N$ Engl f Med 1984;310:435-41.

15 Falconer DS. The inheritance of liability to certain diseases estimated from the incidence among relatives. Ann Hum Gen 1965;29:51-76.

16 Smith C. Concordance in twins: methods and interpretation. Am $\mathcal{F}$ Hum Genet 1974;26:454-66.

17 McGue $M$. When assessing twin concordance, use the probandwise not the pairwise rate. Schizophr Bull 1992; 18:171-6.

18 Dumon J, Macken J, DeBarsy T H. Concordance for amyotrophic lateral sclerosis in a pair of dizygous twins of consanguineous parents. $\mathcal{F}$ Med Genet 1971;8:113-6.

19 Estrin WJ. Amyotrophic lateral sclerosis in dizygotic twins. Neurology 1977;27:692-4

20 Jokelanien M, Palo J, Lokki J. Monozygous twins discordant for amyotrophic lateral sclerosis. Eur Neurol 1978; 17:296-9.

21 Currier RD, Conwill DE. Influenza and physical activity as possible risk factors for amyotrophic lateral sclerosis: a study of twins. In: Rose FC, Norris FH, eds. ALS. New advances in toxicology and epidemiology. London: SmithGordon, 1990:23-8.

22 Schlesselman JJ. Case-control studies: design, conduct, analysis. Oxford: Oxford University Press, 1982.

23 Tandan R, Bradley WG. Amyotrophic lateral sclerosis: Part 2. Etiological factors. Ann Neurol 1985;18:271-80.

24 Williams DB, Windebank AJ. Motor neuron disease (amyotrophic lateral sclerosis)-subject review. Mayo Clin Proc 1991;66:54-82.

25 Graham AJ, Hawkes $\mathrm{CH}$. Twin study using mortality data: a new sampling method. Int $₹$ Epidemiol 1995;24:758-62.

26 Magnus P, Berg K, Nance WE. Predicting zygosity in Norwegian twin pairs born 1915-60. Clin Genet 1983;24: 103-12.

27 Emery AE. Methodology in medical genetics: an introduction to statistical methods. Edinburgh: Churchill, 1986

28 Allen G, Harvald B, Shields J. Measures of twin concordance. Acta Genetica Statistica 1987;17:475-81.

29 Kendler KS. Limitations of the ratio of twin concordance rates in monozygotic and dizygotic twins [letter]. Arch Gen Psychiatry 1983;46:477-8.

30 Altman D.G. Practical statistics for medical research. London: Chapman and Hall, 1991.

31 Office of Population Censuses and Surveys. Birth statistics in England and Wales. London: Her Majesty's Stationary Office, 1984.

32 Bailey A, Le Couteur A, Gottesman I, Bolton P, Simonoff E, Yuzda E, Rutter M. Autism as a strongly genetic disorder: evidence from

33 Phillips DIW. Twin studies in medical research: can they tell us whether diseases are genetically determined? Lancet 1993;341:1008-9.

34 Leslie RDG, Pyke DA. Twin studies in medical research [letter]. Lancet 1993;341:1418.

35 Duffy DL. Twin studies in medical research [letter]. Lancet 1993;341:1418-19.

36 Macdonald AM. Twin studies in medical research [letter] Lancet 1993;341:1419.

37 Christensen K, Vaupel JW, Holm NV, Yashin AI. Mortality among twins after age 6: fetal origins hypothesis versus twin method. $B M F$ 1995;310:432-6.

38 Bundy S. Use and limitations of twin studies. 7 Neurol 1991;238:360-4.

39 Lykken DT, Tellegen A, Derubeis R. Volunteer bias in twin research: the rule of two thirds. Soc Biol 1978; 25:1-9.

40 Lykken DT, McGue M, Tellegen A. Recruitment bias in twin research: the rule of two-thirds reconsidered. Behav Genet 1987;17:343-62.

41 Mumford CJ, Wood NW, Kellar-Wood H, Thorpe JW, Miller DH, Compston DAS. Multiple sclerosis in twins: the British Isles survey. Neurology 1994;44:11-5.

42 French Research Group on Multiple Sclerosis. Multiple sclerosis in $\mathbf{5 4}$ twinships: concordance rate is independent of zygosity. Ann Neurol 1994;32:724-7.

43 Ebers GC, Bulman DE, Sadovnick AD, Paty DW, Warren $\mathrm{S}$, Hader W, et al. A population-based study of multiple S, Hader W, et al. A population-based study of mutain
sclerosis in twins. N Engl f Med 1986;315:1638-42.

44 O'Malley F, Dean G, Elian M. Multiple sclerosis and motor neurone disease: survival and how certified after motor neurone disease: survival and how certified
death. $\mathcal{F}$ Epidemiol Community Health 1987;41:14-7.

45 Buckley J, Warlow C, Smith P, Hilton-Jones D, Irvine S, Tew JR. Motor neurone disease in England \& Wales Tew JR. Motor neurone disease in England \& Wales
$1959-79$. $f$ Neurol Neurosurg Psychiatry 1983;46: 1959-79.

46 Juergens SM, Kurland LT, Okazaki H, Mulder DW. ALS in Rochester Minnesota 1925-77. Neurology 1980;30: 463-70

47 Hoffman PM, Brody JA. The accuracy of mortality statistics in clinically proven amyotrophic lateral sclerosis. Trans Am Neurol Assoc 1970;95:261-3.

48 Smith C. Heritability of liability and concordance in monozygotic twins. Ann Hum Gen 1970;34:85-91.

49 Office of Population Censuses and Surveys, Health and Safety Executive. Drever F, ed. Appendix 4 of occupational health: decennial supplement, series DS No 10. London: Her Majesty's Stationary Office, 1995:329. 
50 Hawkes CH, Cavanagh JB, Fox AJ. Motor neurone disease: a disorder secondary to solvent exposure. Lancet 1989;i:73-5.

51 Gunnarson L-G, Linberg G, Söderfeldt B, Axelson O Amyotrophic lateral sclerosis in Sweden in relation to occupation. Acta Neurol Scand 1991;83:394-8.

52 Chió A, Meineri P, Tribolo A, Schiffer D. Risk factors in motor neuron disease: a case-control study. Neuroepidemiology 1991;10:174-84.

53 Deapen DM, Henderson BE. A case-control study of amyotrophic lateral sclerosis. Am F Epidemiol 1986;123: 790-9.

54 Pall HS, Williams AC, Waring R, Elias E. Motor neurone disease as manifestation of pesticide toxicity. Lancet 1987;19:685.

55 Scottish Motor Neurone Disease Research Group. The Scottish motor neurone disease register: a prospective study of adult onset MND in Scotland. Methodology, demography, and clinical features of incident cases
1989. F Neurol Neurosurg Psychiatry 1992;55:536-41.

56 Yoshida S, Mulder DW, Kurland LT, Chu CP, Okazaki H.

Follow-up study on amyotrophic lateral sclerosis

in Rochester Minnesota, 1925 through 1984

Neuroepidemiology 1986;5:61-70.

57 Tysnes O-B, Aarli JA. Epidemiology of amyotrophic lateral sclerosis in Hordaland county, western Norway. In: Rose Sclerosis in Hordaland county, western Norway. In: Rose CF, ed. New evidence in $M N D / A L S$ research: advances
$A L S / M N D: 2$. London: Smith-Gordon 1991;47-54.

58 Lilienfield DE, Chan E, Ehland J, Godbold J, Landrigan PJ, Marsh G, Perl DP. Rising mortality from motor neuron disease in the USA, 1962-84. Lancet 1989;710-2.

59 Hawkes CH, Fox AJ, Graham AJ. Cohort analysis in motor neurone disease [abstract]. $\mathcal{F}$ Neurol Neurosurg Psychiatry 1992;55:420.

60 Calne DB, Eisen A, McGeer E, Spencer P. Alzheimer's disease, Parkinson's disease, and motor neurone disease: abiotrophic interaction between ageing and environment? Lancet 1986;ii: 1067-70. 